\title{
Oral phentolamine for treatment of ventricular premature contractions
}

\author{
Lawrence Gould, Robert F. Gomprecht, and Mohammad Zahir \\ From the Medical Service of the Misericordia-Fordham Hospital Affiliation, \\ 600 East 233rd Street, Bronx, New York 10466, U.S.A.
}

Phentolamine was administered orally to $2 I$ patients with persistent ventricular premature contractions. In 15 patients the ventricular premature contractions were abolished, while in 5 a conspicuous decrease in their frequency was observed. The effective dose of phentolamine was either 50 or $75 \mathrm{mg}$. administered 4 times a day in all but 2 of the patients. The maximum antiarrhythmic effect was seen in 2 or 3 days in the majority of patients. The favourable antiarrhythmic effects persisted in all of the successfully treated patients when they were treated for an additional week. The drug produced transient gastrointestinal symptoms in 3 patients. Hypotension was not observed.

These studies indicate that phentolamine warrants further study as an antiarrhythmic agent.

In his experimental work on dogs, Leimdorfer (1952, 1953) showed that the intravenous administration of phentolamine prevented nicotine sulphate and epinephrine induced arrhythmias and converted methacholine induced atrial flutter, fibrillation, and atrioventricular nodal rhythm to normal sinus rhythm. He further showed that phentolamine administration prevented the appearance of pronounced bradycardia during electrical stimulation of the vagus nerve.

In an additional study (Ettinger et al., - 1969), ro normal dogs were rapidly digitalized with ouabain until electrocardiographic abnormalities of rhythm occurred. Phentol2 amine, infused intravenously at $0.3 \mathrm{mg}$. $/ \mathrm{min}$., rapidly abolished ventricular tachycardia in 4

- of 5 cases, ventricular premature contractions in 3 cases, and complete heart block in I case.

- It increased the rate in I case of sinus bradycardia.

- Phentolamine has recently been used to

- treat cardiac arrhythmias in man (Gould et $a l ., 1969 \mathrm{~b})$. When the drug was infused intra-

- venously at $0.3 \mathrm{mg}$. $/ \mathrm{min}$. to 25 patients with digitalis as well as non-digitalis induced

* ventricular premature contractions, all but one responded with a decrease or an abolition

- in the number of extrasystoles.

These observations led us to consider the

use of phentolamine administered orally as _an antiarrhythmic agent. This mode of

Received 18 May 1970. administration would make the drug more useful clinically.

In the present paper, we report our experience with the use of oral phentolamine in patients with ventricular premature contractions.

\section{Method}

Persistent ventricular premature contractions, of at least a few days duration, were treated 21 times in 18 patients. Three patients (Cases 2, 6, and 7) received two separate courses of phentolamine. Four of the patients were taking digoxin and 2 were on procainamide. The rest were not taking any medication. No patient who had recently sustained a myocardial infarction was included in the study. All the patients were in sinus rhythm. None was in overt congestive heart failure, but all had cardiac disease. The underlying pathological states were arteriosclerotic heart disease in 14 patients, primary myocardial disease in 2 patients, and cor pulmonale in 2 patients.

The initial dose of phentolamine was $50 \mathrm{mg}$. four times a day, and this was given for two days. If there was not a conspicuous decrease in the number of ventricular premature contractions, as determined by the electrocardiogram, then $75 \mathrm{mg}$. phentolamine was given four times a day for an additional two days. If there was still no favourable response, 100 mg. phentolamine was given four times a day for two more days. A lack of response after the six days of treatment was considered a therapeutic failure. When the effective dose was achieved, it was continued for seven days in order to determine if the favourable antiarrhythmic effect persisted. For those patients 
receiving digitalis or procainamide, no adjustment in the dose of these drugs was made at the time phentolamine was given.

An electrocardiogram was recorded from one to three times a day to determine if the patient was deriving any benefit from the drug. Daily blood pressures were also obtained.

The procedure was explained in detail to the subjects and the investigative nature of the study was stressed. An informed consent was then obtained from all the patients.

\section{Results}

In 15 patients, ventricular premature contractions were abolished, while in 5 decrease in their frequency was observed. Only one patient failed to respond to oral phentolamine. The effective dose of phentolamine was either 50 or $75 \mathrm{mg}$. four times a day in all but 2 patients. The maximum antiarrhythmic effect was seen in I to 5 days, however, the majority of the patients responded in 2 or 3 days. The favourable antiarrhythmic effects persisted in all the successfully treated patients when they were treated for an additional week. The frequency of the premature contractions before and during therapy are listed in the Table.

The only side-effects seen were of gastrointestinal origin. During the first two days of treatment diarrhoea developed in one patient, anorexia in a second patient, and a vague abdominal discomfort in a third patient. However, the therapy was continued without difficulty and the symptoms abated.
No effect on the blood pressure was observed during the course of therapy.

\section{Discussion}

The administration of $5 \mathrm{mg}$. phentolamine intravenously to normal dogs, each with a strain gauge arch attached to the right ventricle, will increase the ventricular contractile force (Gould, Zahir, and Ettinger, 1969a). This positive inotropic response in animals has also been shown in humans by employing the left ventricular dp/dt (Gould et al., 1969a). This measurement is very increased after the administration of phentolamine. The administration of this drug, at an infusion rate of $0.3 \mathrm{mg}$. per minute, to patients in congestive heart failure produces a striking haemodynamic improvement. The cardiac output, cardiac rate, systemic pressure, and stroke index increase, while the pulmonary artery pressure, systemic peripheral resistance, left ventricular end-diastolic pressure, and left ventricular end-diastolic volume fall.

This improvement in cardiac function may be explained by the recent observations of Dairman and his associates (I969). They administered phentolamine (5 mg./kg.) to rats. At the height of alpha-receptor blockade, the conversion of a tracer dose of tyrosine $-{ }^{14} \mathrm{C}$ to norepinephrine in the heart, brain, and adrenal gland was increased threefold, with no alteration in specific activity of tyrosine in

TABLE Frequency of ventricular premature contractions (VPC)

\begin{tabular}{|c|c|c|c|c|c|c|}
\hline $\begin{array}{l}\text { Case } \\
\text { No. }\end{array}$ & $\begin{array}{l}\text { Underlying } \\
\text { condition }\end{array}$ & Other drugs & $\begin{array}{l}\text { Control observation } \\
\text { frequency of VPC }\end{array}$ & $\begin{array}{l}\text { Effective dose } \\
\text { (mg. given } 4 \\
\text { times a day) }\end{array}$ & $\begin{array}{l}\text { When maximum } \\
\text { effect seen (day) }\end{array}$ & $\begin{array}{l}\text { During phentolamine } \\
\text { treatment-frequency } \\
\text { of VPC }\end{array}$ \\
\hline $\begin{array}{l}\left.\begin{array}{l}1 \\
2 \\
2\end{array}\right\} \\
3 \\
4 \\
5 \\
6 \\
6 \\
7 \\
7 \\
8 \\
9 \\
10 \\
11 \\
12 \\
13 \\
14 \\
15 \\
16 \\
17 \\
18\end{array}$ & $\begin{array}{l}\text { ASHD } \\
\text { ASHD } \\
\text { ASHD } \\
\text { ASHD } \\
\text { ASHD } \\
\text { Cor pulm. } \\
\text { ASHD } \\
\text { ASHD } \\
\text { PMD } \\
\text { PMD } \\
\text { ASHD } \\
\text { Cor pulm. } \\
\text { ASHD } \\
\text { ASHD } \\
\text { ASHD } \\
\text { ASHD } \\
\text { PMD } \\
\text { ASHD } \\
\text { ASHD } \\
\text { ASHD } \\
\text { ASHD }\end{array}$ & $\begin{array}{l}\text { None } \\
\text { None } \\
\text { None } \\
\text { None } \\
\text { None } \\
\text { None } \\
\text { Digitalis } \\
\text { Digitalis } \\
\text { Procainamide } \\
\text { Procainamide } \\
\text { None } \\
\text { None } \\
\text { Procainamide } \\
\text { Digitalis } \\
\text { None } \\
\text { None } \\
\text { Digitalis } \\
\text { None } \\
\text { Digitalis } \\
\text { None } \\
\text { None }\end{array}$ & $\begin{array}{l}\text { Every other beat } \\
\text { Every other beat } \\
\text { Every other beat } \\
\text { Every third beat } \\
\text { Every other beat } \\
9 / \mathrm{min} . \\
30 / \mathrm{min} \text {. } \\
25 / \mathrm{min} \text {. } \\
\text { Every other beat } \\
\text { Every other beat } \\
\text { Every other beat } \\
30 / \mathrm{min} \text {. } \\
40 / \mathrm{min} \text {. } \\
\text { Io/min. } \\
\text { Every other beat } \\
\text { Every fourth beat } \\
\text { I } 8 / \mathrm{min} \text {. } \\
\text { Every fourth beat } \\
\text { Every sixth beat } \\
\text { Every other beat } \\
\text { Every other beat }\end{array}$ & $\begin{array}{r}75 \\
50 \\
50 \\
100 \\
75 \\
100 \\
75 \\
75 \\
75 \\
75 \\
75 \\
75 \\
75 \\
75 \\
75 \\
50 \\
75 \\
50 \\
50 \\
50\end{array}$ & $\begin{array}{l}3 \\
1 \\
1 \\
5 \\
3 \\
5 \\
3 \\
3 \\
3 \\
4 \\
3 \\
4 \\
3 \\
4 \\
4 \\
2 \\
3 \\
2 \\
2 \\
2\end{array}$ & $\begin{array}{l}\text { None } \\
\text { None } \\
\text { None } \\
\text { None } \\
\text { Every other beat } \\
\text { None } \\
\text { I/min. } \\
\text { I/min. } \\
\text { None } \\
\text { None } \\
\text { 2/min. } \\
\text { None } \\
\text { None } \\
\text { None } \\
\text { None } \\
\text { None } \\
\text { 5/min. } \\
\text { I/min. } \\
\text { None } \\
\text { None } \\
\text { None }\end{array}$ \\
\hline
\end{tabular}


blood and tissues. From these studies, Dairman concluded that receptor blockade led to increased synthesis and release of norepinephrine in the three organs that were measured. Our studies with smaller doses of phentolamine have indicated a positive inotropic effect. In view of the findings of Dairman and his co-workers, it could reasonably be assumed that the inotropic effect is a direct one, resulting from increased production of catecholamines in the myocardium. Phentolamine is also known to be an alpha-adrenergic blocking agent. This is based on the observation that it can antagonize or even reverse the pressor response to epinephrine (Meier et al., 1949; Freis, MacKay, and Oliver, 195 I): the blockade thus produced is relatively transient. A mild sympatholytic action becomes manifest only with the use of very large amounts of this agent (Walker et al., 1950). The drug also has a peripheral vasodilating effect which is not blocked by atropine (Goodman and Gilman, 1955). The drug's relatively weak sympathetic blocking action as well as its antagonism to the circulatory catecholamines cannot adequately explain the striking vasodilatation that results from its use under normal resting conditions. Taylor et al. (1965) believe that a direct relaxing effect on the vascular smooth muscle plays the dominant role in the production of this conspicuous peripheral vasodilatation.

The antiarrhythmic action of phentolamine is not fully understood. In some subjects the

- improvement in left ventricular function may lead to a decrease in the number of ventricular premature contractions. The increased production of catecholamines, as described by

- Dairman and his associates, could lead one to conclude that the administration of phentolamine might produce arrhythmias. However,

- an alternative explanation should also be considered. Re-entry is believed to be an impor-

$\checkmark$ tant mechanism in the production of ventricular premature contractions. The theory of re-

- entry states that in the heart muscle there are one or more areas in which recovery from the refractory state is slower than normal. The administration of phentolamine, with its concomitant increase in catecholamines, could - theoretically reverse this pattern of disturbed conduction and abolish the ventricular prema- ture contractions. Hoffman (1967) has investigated the effects of catecholamines on - conduction. He observed that if the transmembrane potential of Purkinje fibres is low

2 because of the action of drugs or pathological processes, catecholamines in proper concentration can increase resting potential and improve conduction. Moreover, they may do this without causing much if any increase in automaticity.

Phentolamine, administered orally, was effective in abolishing or decreasing the number of ventricular extrasystoles. This was accomplished in 2 to 3 days in most of the patients, and was associated with a concomitant improvement in their clinical state. The antiarrhythmic effect persisted as long as phentolamine was given. However, long-term studies will have to be performed to determine if tachyphylaxis will be a problem.

Phentolamine can be effectively used in conjunction with other antiarrhythmic agents. In Case 7, $750 \mathrm{mg}$. procainamide, administered four times a day, was not effective in suppressing the ventricular bigeminy. The addition of phentolamine to the regimen led to an abolition of the extrasystoles. Four days after stopping phentolamine, in spite of the continuance of procainamide, ventricular bigeminy recurred. However, the second course of treatment with phentolamine again led to complete suppression of the ventricular premature contractions. This supports the contention that the favourable antiarrhythmic action in this patient was due to phentolamine and not to chance.

The first patient in the study was of considerable interest because the usual antiarrhythmic agents were ineffective in controlling the frequent ventricular premature contractions. $400 \mathrm{mg}$. quinidine, $100 \mathrm{mg}$. phenytoin sodium, and I g. procainamide had been given four times a day separately and in various combinations without success. In addition the patient was digitalized; however, this also had no effect on the frequency of the extrasystoles. Though the study was designed to follow the patients for only I week after successful treatment, we decided to continue phentolamine $75 \mathrm{mg}$. four times a day in this patient, since no alternative mode of therapy was successful. A weekly electrocardiogram has been taken in the outpatient clinic for the past five months, and she remains asymptomatic and free of any ventricular premature contractions.

Chronic oral administration of phentolamine was initially used by Moyer and Caplovitz (1953) in the treatment of hypertensive disease. However, no significant fall in the blood pressure was observed. The starting dose used by these authors was $50 \mathrm{mg}$. every 6 hours. In order to reduce the blood pressure, the dose of the drug was increased up to $900 \mathrm{mg}$. a day; however, gastrointestinal manifestations appeared in many of the patients. Large doses of phentolamine are known to exert prominent direct 
stimulant actions on the intact gastrointestinal tract, and cause hyperperistalsis and diarrhoea in animals and man. These motor responses are blocked by atropine, a fact that suggests that they are cholinergic (Goodman and Gilman, I955).

All our patients demonstrated an antiarrhythmic effect with relatively small doses of phentolamine. Indeed 200 or $300 \mathrm{mg}$. a day was the effective dose in all but 2 of the patients. Since the gastrointestinal effects are dose-related, the small amount of phentolamine used in our study minimized the gastrointestinal complications.

The present study has shown that phentolamine, administered orally, can diminish or abolish ventricular premature contractions. It now seems reasonable to widen the clinical experience with this drug.

\section{References}

Dairman, W., Gordon, R., Spector, S., Sjoerdsma, A., and Udenfriend, S. (1969). Effect of alpha-blockers on catecholamine biosynthesis. Federation Proceedings, 27, 240.

Ettinger, S., Gould, L., Carmichael, J. A., and Tashijian, R. J. (1969). Phentolamine: use in digitalis-induced arrhythmias. Canine experiments. American Heart fournal, 77, 636.

Freis, E. D., MacKay, J. G., and Oliver, W. F. (195I). The effect of 'sympatholytic' drugs on the cardiovascular responses to epinephrine and nonepinephrine in man. Circulation, 3, 254.
Goodman, L. S., and Gilman, A. (1955). The Pharmacological Basis of Therapeutics, 2nd ed., p. 584. Macmillan, New York.

Gould, L., Zahir, M., and Ettinger, S. (1969a). Phentolamine and cardiovascular performance. British Heart fournal, 31, 154.

,-, Shariff, M., and Giuliani, M. G. (1969b). Treatment of cardiac arrhythmias with phentolamine. American Heart fournal, 78, 189.

Hoffman, B. F. (1967). Autonomic control of cardiac rhythm. Bulletin of the New York Academy of Medicine, 43, 1087.

Leimdorfer, A. (1952). Prevention and abolition of cardiac arrhythmias by Regitine. American fournal of Physiology, 171, 742.

- (1953). Abolition of cardiac arrhythmias by Regitine. Archives Internationales de Pharmacodynamie et de Thérapie, 96, 249.

Meier, R., Yonkman, F. F., Craver, B. N., and Gross, F. (1949). A new imidazoline derivative with marked adrenolytic properties. Proceedings of the Society for Experimental Biology and Medicine, 71, 70.

Moyer, J. H., and Caplovitz, C. (1953). The clinical results of oral and parenteral administration of 2- $\left(N^{\prime}-\right.$ p-tolyl- $N^{\prime}-m$-hydroxyphenylaminomethyl imidazoline hydrochloride (Regitine) in the treatment of hypertension and an evaluation of the cerebral haemodynamic effects. American Heart fournal, 45, 602.

Taylor, S. H., Sutherland, G. R., MacKenzie, G. J., Staunton, H. P., and Donald, K. W. (I965). The circulatory effects of intravenous phentolamine in man. Circulation, 31, 74I.

Walker, H. A., Heymans, C., Wilson, S., and Richardson, A. P. (1950). The effect of C-7337 on carotid sinus reflex and on pressor and peripheral vascular actions of epinephrine and nor-epinephrine. fournal of Pharmacology and Experimental Therapeutics, 98, 33. 